\title{
Controversies in Management of Diabetes in Patients with Coronary Heart Disease
}

\author{
N.A. Abdella \\ Department of Medicine, Faculty of Medicine, Kuwait University, Kuwait
}

\section{Key Words}

Type 2 diabetes · Coronary heart disease - Insulin . Sulphonylurea. Selectivity

\begin{abstract}
A global epidemic of type 2 diabetes exists and in the near future it may be closely associated with an epidemic of cardiovascular disease. Since the diabetic population is at risk of developing cardiovascular disease, diabetes management should target tight glycaemic control. Two controversial issues in the management of diabetics with coronary heart disease (CHD) are discussed in this review. Firstly, exogenous insulin administration and increased risk of cardiovascular disease, and, secondly, the effect of sulphonylurea treatment on potassium ATP channels and risk of myocardial ischaemia. The consensus of opinion is that high circulating serum insulin level is simply a marker of an insulin-resistant state and therefore does not have a direct role in the pathogenesis of atherosclerosis in diabetic patients. However, overwhelming evidence exists for the linear association between worsening glycaemic control and increased risk for coronary heart disease. The United Kingdom Prospective Diabetes Study reported intensive blood glucose control decreased the risk of myocardial infarction by $16 \%$. The benefits of tight glycaemic control out-
\end{abstract}

weighs the theoretical concept of hyperinsulinaemia being atherogenic. Safety concerns about sulphonylureas date back to 1970 . The mechanism of action of sulphonylureas by closure of potassium ATP channels identified in pancreatic beta cells, cardiomyocytes and vascular smooth muscle cells caused great concern about safety because of the risk of developing myocardial ischaemia. Brief episodes of cardiac ischaemia render the heart more resistant to subsequent ischaemic events, this phenomenon is called 'ischaemic preconditioning'. Activation of potassium ATP channels completely mimicked the preconditioning phenomena; moreover, blocking these channels with some of the sulphonylurea compounds abolished this protective effect. The concept of selectivity of sulphonylurea compounds therefore emerged and the choice of drug should be based on this fact. Every compound should be studied individually for its efficacy and safety vis-à-vis the relevant end points for type 2 diabetes, i.e. cardiovascular morbidity and mortality.

Copyright $@ 2002$ S. Karger AG, Basel

\begin{tabular}{llll}
\hline KARGER & @ 2002 S. Karger AG, Basel & & $\begin{array}{l}\text { Dr. Nabila Abdella } \\
\text { Department of Medicine }\end{array}$ \\
$\begin{array}{l}\text { Fax + 41 61 306 1234 } \\
\text { E-Mail karger@karger.ch }\end{array}$ & $\begin{array}{l}\text { Accessible online at: } \\
\text { www.karger.com }\end{array}$ & www.karger.com/mpp & Faculty of Medicine, Kuwait University \\
13110 Safat (Kuwait) & Tel. +965 531 9596, Fax +965 533 8907, E-Mail nabdella12@yahoo.com
\end{tabular}




\section{Introduction}

Existence of the global epidemic of diabetes mellitus is well known since over 150 million people worldwide suffer from the disease and a conservative estimate is that this number will be doubled by the year 2025 [1]. Type 2 diabetes accounts for most of the current and the predicted figures, and its close association with cardiovascular disease seems to emerge from a common soil, insulin resistance. Hence, it is believed that in the near future this global epidemic of type 2 diabetes will be closely associated with an epidemic of cardiovascular disease. Furthermore, diabetes mellitus increases mortality risk and reduces life expectancy, the leading cause of death being cardiovascular disease [2,3]. The 16-year follow-up of the Framingham study [4] demonstrated an equal risk of cardiovascular morbidity and mortality among diabetic men and women. Since the diabetic population is at risk of developing cardiovascular disease, the approach to diabetes management should target a tight glycaemic control because of the recent evidence for its beneficial effects [5, 6]. In this paper, two controversial issues concerning the management of diabetics with cardiovascular disease are reviewed.

\section{Exogenous Insulin Administration and Cardiovascular Risk in Type 2 Diabetes mellitus}

Early epidemiological studies [7, 8] reported insulin as an independent risk factor for cardiovascular disease. The 5-year follow-up analysis of the Helsinki Policemen Study [9] supported the hypothesis that high circulating level of insulin is related (although probably indirectly) to an increased incidence of complications of atherosclerosis such as myocardial infarction and angina pectoris. A current controversial issue is whether intensive insulin treatment of diabetes decreases the risk for cardiovascular complications by lowering glucose levels or increases the risk by postulated direct atherogenic effects of high circulating levels of exogenous insulin.

A growing number of investigators believe that the high circulating serum insulin level is simply a marker for an insulin-resistant state and therefore does not have a direct role in the pathogenesis of atherosclerosis. Although some in vitro experiments and animal models of atheroma formation have shown that high insulin level leads to accelerated plaque formation [10,13], clinical evidence does not exist as yet. A substantial amount of indirect data suggests that hyperglycemia may have a causal role in atheroma formation $[14,15]$ and may have a prothrombotic effect on the coagulation cascade [16]. Improved glycemic control has been shown to lower lowdensity lipoprotein cholesterol levels [17, 18], which theoretically should lower the risk of developing CHD for patients with diabetes. Prospective epidemiologic studies $[19,20]$ that had analyzed the relationship between the fasting blood glucose (FBG) level or the glycosylated haemoglobin $\mathrm{A} 1_{\mathrm{C}}\left(\mathrm{HbA} 1_{\mathrm{c}}\right)$ level and the risk of $\mathrm{CHD}$ showed a linear association between worsening glycemic control and an increased risk for CHD, although Singer et al. [21] disagreed. In the most compelling study, the Wisconsin Epidemiological Study of Diabetic Retinopathy, investigators analyzed cause-specific mortality over a 10 -year period and found that death due to CHD was much more common in patients with worse glycemic control (relative risk, 1.10 for each $1 \%$ increase in $\mathrm{HbAl}_{c} ; 95 \%$ confidence interval, 1.07-1.17) [22] than in others. In 3 randomized controlled trials of glycemic control in type 2 diabetes, a sufficient number of cardiovascular events were recorded to make meaningful comparisons between treatment groups. Too few events were recorded in the Kumamoto study [23] because of the exclusion of patients with hypertension, hypercholesterolemia and obesity. In the University Group Diabetes Program (UGDP) [24], no significant difference was found in the rate of myocardial infarction between the intensive and conventional treatment groups (20.6 vs. $20.2 \%$, respectively, $\mathrm{p}=1.00$, Fisher's exact test), despite a much higher prevalence of cardiac risk factors in the intensive treatment group. A shorter study, 'Diabetes mellitus, Insulin Glucose Infusion in Acute Myocardial Infarction Study Group (DIGAMI) [25]', tested the hypothesis that intensive metabolic treatment with insulin glucose infusion followed by multidose insulin treatment in patients with diabetes mellitus and acute myocardial infarction improved the prognosis. The authors concluded that insulin treatment in diabetic patients with acute myocardial infarction improved longterm survival by nearly a third, and the effect seemed to last for at least 3.5 years. Much more importantly, the absolute reduction in mortality was $11 \%$, implying one saved life for 9 patients treated according to the insulin glucose infusion protocol. The reduction in mortality was most apparent in patients without previous insulin treatment and at a low cardiovascular risk.

The United Kingdom Prospective Diabetes Study (UKPDS) [6] projected to have a 91\% power to detect $20 \%$ treatment group difference in the first cardiovascular outcome among the type 2 diabetic population reported that an intensive blood glucose control policy 
with an $11 \%$ reduction in median $\mathrm{HbAl}_{\mathrm{c}}$ over the first 10 years decreased the risk for myocardial infarction by $16 \%(\mathrm{p}=0.0052)$, including non-fatal and fatal myocardial infarction and sudden death. The diabetes-related mortality and all-cause mortality did not differ between the intensive and conventional groups. The study did not have sufficient power to exclude a beneficial effect on fatal outcomes. It is commonly stated that insulin is a risk factor for atherosclerosis (cardiovascular or CHD) and in the insulin resistance syndrome, hyperinsulinaemia appears to be the motor that drives the other components of the syndrome - hypertension and dyslipidaemia [26]. Jarret reported several studies including his own analysis of the Bedford Study [27] that showed no significant associations with insulin levels and CHD in diabetes compared to the control group. A possible explanation is the significant associations between insulinaemia and several well-documented risk factors of CHD: elevated blood pressure and very-low-density lipoprotein-triglyceride levels, reduced high-density lipoprotein-cholesterol levels, obesity, and visceral fat [28]. Furthermore, evidence exists that associations with cardiovascular risk factors are stronger for insulin-like molecules than for insulin itself [29].

An attractive hypothesis is that of Hales and Barker [30] which suggests a fetal origin for associations seen in later life, including those between insulin-like molecules and undoubted cardiovascular risk factors.

The benefits of tight glycaemic control outweigh the theoretical concept of hyperinsulinaemia being atherogenic and management should target associated risk factors: obesity, hypertension and hyperlipidaemia.

\section{Does Sulphonylurea Treatment of Type 2 Diabetes mellitus Contribute to the Cardiovascular Risk?}

Historically, the concern about the safety of sulphonylurea (SU) dates back to 1970 when the UGDP [31] concluded that tolbutamide treatment caused increased cardiovascular mortality, a study which at the time led to curtailment of oral antidiabetic treatment in USA, but was received with scepticism in Europe. Later criticism of its methodology reduced the impact of the study. However, the question of the safety of SU in type 2 diabetic patients with CHD has been reopened because of new experimental data. SU has been prescribed by three generations of diabetologists. SU provided alternative therapy to insulin for type 2 diabetes. However, despite their relatively long use it is only recently that the mechanism of action of this therapeutic class of drugs at molecular level has been clearly understood. Sulphonylureas stimulate insulin secretion in type 2 diabetic patients by blocking ATP-sensitive $\mathrm{K}_{\mathrm{ATP}}$ channels in the pancreatic $\beta$-cell membrane by binding to the SU receptor (SUR1) subunit of the channel. $\mathrm{K}_{\mathrm{ATP}}$ channels are also present in a range of extrapancreatic tissues, but may contain alternative types of SUR subunit (SUR2A in heart and SUR2B in smooth muscle). The SU sensitivity of $\mathrm{K}_{\mathrm{ATP}}$ channels varies with the type of SUR subunit: thus, gliclazide and tolbutamide potently block the $\beta$-cell (SUR1), but not the cardiac (SUR2A) or smooth muscle (SUR2B) types of $\mathrm{K}_{\mathrm{ATP}}$ channel. In contrast, glibenclamide and glimepiride block all three types of $K_{A T P}$ channel with similar potency. Therefore, administration of a SU compound such as glibenclamide that has a $\mathrm{K}_{\mathrm{ATP}}^{+}$-channel-blocking effect should be expected to increase ischaemic damage and abolish the protective action of channel openers.

It is known from in vitro as well as in vivo studies that activation of $\mathrm{K}_{\mathrm{ATP}}^{+}$channels constitutes an important cardioprotective mechanism against ischaemic damage. Since the discovery of $\mathrm{K}_{\mathrm{ATP}}^{+}$channels in the heart [8], numerous investigators have evaluated their role in cardiac adaptation to ischaemic insults. The high levels of ATP in the normal cardiomyocyte probably keep most $\mathrm{K}_{\mathrm{ATP}}^{+}$channels in the closed state [32], but these are opened when the level is lowered thereby leading to multiple changes in cardiac metabolism, electrical activity and mechanical function, which results from ischaemia. Soon after the onset of ischaemia, activation of outward flow of $\mathrm{K}^{+}$currents through the $\mathrm{K}_{\mathrm{ATP}}^{+}$channels results in earlier repolarization of the myocyte and shortening of the action potential, which leads to a reduction of calcium influx through voltage-gated calcium channels [38-41]. The resulting decrease in contractility protects the ischaemic cardiomyocyte by reducing its oxygen demand. In addition, opened arterial wall $\mathrm{K}_{\mathrm{ATP}}^{+}$channels during ischaemia decrease the vascular resistance, thus increasing coronary blood flow [42, 43]. Another consequence of ischaemia is intracellular accumulation of adenosine derived from the breakdown of ATP, which may leak out from cells and activate plasma membrane-A1 receptors in an autocrine manner, thus leading to opening of $\mathrm{K}_{\mathrm{ATP}}^{+}$channels [44, 45]. Adenosine has been suggested to be a major cardioprotective agent, it seems to mediate its effect through a variety of mechanisms, including direct vasodilatory and anti-arrhythmic actions, attenuation of the heart response to sympathetic stimuli, inhibition of platelet aggregation, 
and reduction of free radical formation [46-48]. The latter may be specially important in the protection against post-infarct reperfusion injury, believed to be caused by the burst of free radicals on reoxygenation.

Brief episodes of ischaemia render the heart more resistant to subsequent ischaemic events, with marked reduction in infarct size and contractile dysfunction [49, 50]. This phenomenon, called 'ischaemic preconditioning, operates in most species including man [51, 52]. Activation of $\mathrm{K}_{\mathrm{ATP}}^{+}$channels completely mimicked the preconditioning, moreover, blocking the channels with antagonists such as glibenclamide abolished the protective effect of preconditioning [53, 54]. Adenosine also seems to be important for preconditioning: short-term infusion of adenosine reduced the extent of myocardial necrosis in dogs with the same efficacy as preconditioning, the effect being mediated through a $\mathrm{K}_{\mathrm{ATP}}^{+}$-channelrelated mechanism, blocked by glibenclamide pretreatment $[55,56]$. Preconditioning is not limited to the heart, it is probably a major protective mechanism in many other tissues.

The other effects of SU on cardiovascular risk factors should be taken into consideration, namely lowering lipid levels. It has been shown that SU lowers plasma total cholesterol, total triglyceride, VLDL cholesterol, LDL cholesterol and apolipoprotein B [57]. In some [58] but not all [59] studies HDL cholesterol was lower in patients treated with insulin, despite comparable glycaemic control. Most of these investigations were conducted with gliclazide. In addition, gliclazide has been shown to inhibit thrombus formation, improve fibrinolysis and reduce platelet adherence and aggregation [60].

The UKPDS study [6] recruited 3,867 newly diagnosed type 2 diabetic patients into a multi-centre randomized controlled trial that sought to compare the effects of intensive blood glucose control (with SU or insulin) with conventional treatment (diet) on risk of microvascular or macrovascular complication in diabetes. A total of 1,138 patients and 2,729 patients were, respectively, assigned conventional and intensive treatment in 23 centres in the UK. The study end-points were: diabetes-related end points, diabetes-related death, and all-cause mortality. The results suggested that intensive blood glucose control significantly decreased the risk of microvascular, but not macrovascular disease in patients with type 2 diabetes. There was no particular adverse cardiovascular risk with SU or insulin. It would therefore appear that the potential advantage of SU in modulating hyperglycemia far outweighs any theoretical risk from a postulated increased liability to macrovascular disease.

\section{Conclusion}

A great deal of evidence exists that an elevated glucose level alone has been shown to be a risk factor for cardiovascular complications in individuals with diabetes mellitus, most notably demonstrated in the UKPDS and that lowering glucose levels reduces this risk. Therefore, our clinical target should be tight glycaemic control either by insulin therapy or oral hypoglycaemic agents. The choice of a SU agent should be guided on the basis of its selectivity for $\mathrm{K}_{\mathrm{ATP}}^{+}$receptor in particular in the diabetic patient with documented CHD. Every SU drug needs to be studied individually for its efficacy and safety vis-à-vis the relevant end points for type 2 diabetes, i.e. cardiovascular morbidity and mortality rather than study being limited to surrogate markers. Besides glycaemic control, multiple risk management policy that includes obesity, hypertension and hyperlipidaemia would be of utmost importance.

Moreover, most studies indicate that second generation SU may have positive effects on lipid metabolism, platelet function and the coagulation system, hence on the accelerated atherosclerosis of the diabetic. The relative contribution of improved metabolic control has been proven and should be targeted by clinicians. On the basis of currently available data it is difficult to delineate the exact role played by SU in diabetic subjects with CHD. Several million diabetic patients, at an age bracket where cardiovascular morbidity is a realistic expectation, are treated with SU derivatives. It is of utmost importance to determine unequivocally whether SU are beneficial or deleterious for these patients. Therefore, large-scale, welldesigned prospective studies are urgently needed to determine the benefit or harmful effect of SU and to define their role in the treatment of diabetic patients with CHD.
Abdella 


\section{References}

1 Cochram C: Diabetes and cardiovascular disease: Double jeopardy. Diabetes Voice 2001; 46:19-23.

2 Kannel WB, McGee DL: Diabetes and cardiovascular risk factors: The Framingham study. Circulation 1979;59:8-13.

3 Fuller JH, Shipley MJ, Rose G, Jarret RJ, Keen $\mathrm{H}$ : Mortality from coronary heart disease and stroke in relation to degree of glycemia: The Whitehall study. Br Med J 1983;287:867-870.

4 Garcia MJ, Mc Namara PM, Gordon T, Karmel WB: Morbidity and mortality in diabetes in the Framingham population: Sixteen year follow up study. Diabetes 1997;23:105-111.

5 The Diabetes Control and Complications: Trial Research Group: The effect of intensive treatment of diabetes on the development and progression of long term complications in insulin-dependent diabetes mellitus. N Engl J Med 1993;329:977-986.

6 UK Prospective Diabetes Study (UKPDS) Group: Intensive blood glucose control with sulphonylurea or insulin compared with conventional treatment and risk of complications in patients with type 2 diabetes (UKPDS 33). Lancet 1998;352:837-865.

7 Eschwege E, Richard JL, Thibult N, Ducimetiere P, Warnet JM, Claude JR, Rosselin GE Coronary heart disease mortality in relation with diabetes blood glucose and plasma insulin levels: The Paris Prospective Study, ten years later. Horm Metab Res Suppl 1985;15:41-46.

8 Welborne TA, Wearne K: Coronary heart disease and cardiovascular mortality in Busselton with reference to glucose and insulin concentrations. Diabetes Care 1979;2:154-160.

9 Pyörälä K, Savolainen E, Kaukola S, Haapakoski J: Plasma insulin as coronary heart disease risk factor: Relationship to other risk factors and predictive value over 9.5 year follow up of the Helsinki Policeman Study population. Acta Med Scand Suppl 1985;701:38-52.

10 Sato Y, Shiraishi S, Oshida Y, Ishiguro T, Sakamoto N: Experimental atherosclerosis-like lesions induced by hyperinsulinism in Wistar rats. Diabetes 1989;38:91-96.

11 Stout RW: Insulin stimulation of cholestero synthesis by arterial tissue. Lancet 1970;i:248.

12 Stout RW, Buchanan KD, Vallance-Owen J: Arterial lipid metabolism in relation to blood glucose and plasma insulin in rats with streptozotocin-induced diabetes. Diabetologia 1972;8: 398-401.

13 Stout RW, Bierman EL, Ross R: Effect of insulin on the proliferation of cultured primate arterial smooth muscle cells. Circ Res 1975;36: 319-327.

14 Bruno G, Cavallo-Perin P, Bargero G, Borra M, D'Errico N, Pagano G: Association of fibrinogen and glycemic control and albumin excretion rate in patients with non-insulindependent diabetes mellitus. Ann Intern Med 1996;125:653-657.

15 Yegin A, Ozben T, Yegin H: Glycation of lipoproteins and accelerated atherosclerosis in noninsulin-dependent diabetes mellitus. Int J Clin Lab Res 1995;25:157-161.
16 Colwell JA: Vascular thrombosis in type 2 diabetes mellitus. Diabetes 1993;42:8-11.

17 Taskinen MR, Kuusi T, Helve E, Nikkila EA, Yki JH: Insulin therapy induces antiatherogenic changes of serum lipoproteins in non-insulin-dependent diabetes. Arteriosclerosis 1988; 8:168-177.

18 Agardh CD, Nilsson EP, Schersten B: Improvement of the plasma lipoprotein pattern after institution of insulin treatment in diabetes mellitus. Diabetes Care 1982;5:322-325.

19 Gall MA, Borch-Johnsen K, Hougaard P, Nielsen FS, Parving HH: Albuminuria and poor glycemic control predict mortality in NIDDM. Diabetes 1995;44:1303-1309.

20 Nielsen NV, Ditzel J: Prevalence of macro- and microvascular disease as related to glycosylated hemoglobin in type 1 and 2 diabetic subjects: An epidemiologic study in Denmark. Horm Metab Res Suppl 1985;15:19-23.

21 Singer DE, Nathan DM, Anderson KM, Wilson PW, Evans JC: Association of HbAlc with prevalent cardiovascular disease in the original cohort of the Framingham Heart Study. Diabetes 1992;41:202-208.

22 Moss SE, Klein R, Klein BE, Meuer SM: The association of glycemia and cause-specific mortality in a diabetic population. Arch Intern Med 1994;154:2473-2479.

23 Ohkubo Y, Kishikawa H, Araki E, Miyata T, Isami S, Motoyoshi S, Kojima Y, Furuyoshi N, Shichiri M: Intensive insulin therapy prevents the progression of diabetic microvascular complications in Japanese patients with non-insulin-dependent diabetes mellitus: A randomized prospective 6-year study. Diabetes Res Clin Pract 1995;28:103-117.

24 Kilo C, Miller JP, Williamson JR: The Achilles heel of the University Group Diabetes Program. JAMA 1980;243:450-457.

25 Malmberg K: Prospective randomized study of intensive insulin treatment on long term survival after acute myocardial infarction in patients with diabetes mellitus. BMJ 1997;314: 1512-1515.

26 Steven MP: The insulin resistance syndrome: The controversy is dead, long live the controversy. Diabetologia 1994;37:956-958.

27 Jarrett RJ, McCartney P, Keen H: The Bedford Survey. Ten year mortality rates in newly diagnosed diabetics and normoglycaemic controls and risk indices for coronary heart disease in borderline diabetics. Diabetologia 1982;22:79_ 84.

28 Haffner SM, Fong D, Hazuda HP, Pugh JA, Patterson JK: Hyperinsulinemia, upper body adiposity and cardiovascular risk factors in non-diabetics. Metabolism 1988;37:333-345.

29 Nagi DK, Hendra TJ, Ryle AJ, Cooper TM, Temple RC, Clark PM, Schneider AE, Hales CN, Yudkin JS: The relationship of concentrations of insulin, intact proinsulin and 32-33 split proinsulin with cardiovascular risk factors in type 2 (non-insulin-dependent) diabetic subjects. Diabetologia 1990;33:532-537.
30 Hales CN, Barker DJP: Type 2 (non-insulindependent) diabetes mellitus: The thrifty phenotype hypothesis. Diabetologia 1992;35:595601.

31 University Group Diabetes Program: A study of the effects of hypoglycemic agents on vascular complications in patients with adult-onset diabetes. VI. Supplementary report on nonfatal events treated with tolbutamide. Diabetes 1976;25:1129-1152.

32 Noma A: ATP-regulated $\mathrm{K}_{\mathrm{ATP}}^{+}$channels in cardiac muscle. Nature 1983;305:147-148.

33 Fosset M, de Weille J, Green R, Schmid-Antomarchi H, Lazdunski M: Antidiabetic sulfonylurea controls action potential properties in heart cells via high affinity receptors that are linked to ATP-dependent $\mathrm{K}_{\mathrm{ATP}}^{+}$channels. J Biol Chem 1988;263:7933-7936.

34 Grover G, McCullough J, Henry D, Conder M, Sleph P: Anti-ischemic effects of the potassium channel activators pinacidil and cromakalim and the reversal of these effects with the potassium channel blocker glyburide. J Pharmacol Exp Ther 1989;251:98-104.

35 Smits P, Thien T: Cardiovascular effects of sulphonylurea derivatives: Implications for the treatment of NIDDM? Diabetologia 1995;38: 116-121.

36 Edwards G, Weston A: Potassium channel openers and vascular smooth muscle relaxation. Pharmacol Ther 1990;48:237-258.

37 Katz A: Cardiac ion channels. N Engl J Med 1993;328:1244-1251.

38 McPherson C, Pierce G, Cole W: Ischemic cardioprotection by ATP-sensitive $\mathrm{K}^{+}$channels involves high energy phosphate preservation. Am J Physiol 1993;265:H1809-H1818.

39 Lee C: Gating mechanisms of ATP sensitive potassium channels: Implication in reperfusion injury and preconditioning. Cardiovasc Res 1994;28:729-734.

40 Gross GJ, Yao Z, Pieper GM, Auchampach JA: The ATP-regulated potassium channel in ischemia-reperfusion injury. Ann NY Acad Sci 1994;723:71-81.

41 Sanguinetti MC: Modulation of potassium channels by antiarrhythmic and hypertensive drugs. Hypertension 1992;19:228-236.

42 Brayden JE: Hyperpolarization and relaxation of resistance arteries in response to adenosine diphosphate. Circ Res 1991;69:1415-1420.

43 Daut J, Maier-Rudolph W, von Beckerath N, Mehrke G, Gunther K, Goedel-Meinen L: Hypoxic dilatation of coronary arteries is mediated by ATP-sensitive potassium channels. Science 1990;247:1341-1344.

44 Auchampach JA, Gross GJ: Adenosine A1 receptors, $\mathrm{K}_{\mathrm{ATP}}$ channels and ischemic preconditioning in dogs. Am J Physiol 1993;264: H1327-H1336.

45 Kirsch GE, Codina J, Birnbaumer L, Brown AM: Coupling of ATP-sensitive $\mathrm{K}^{+}$channels to A1 receptors by $\mathrm{G}$ proteins in rat ventricular myocytes. Am J Physiol 1990;259:H820H826. 
46 Wainwright CL, Parrat JR: An antiarrhythmic effect of adenosine during myocardial ischemia and reperfusion. Eur J Pharmacol 1988;145: 183-194.

47 Belardinelli L, Linden J, Berne RM: The cardiac effects of adenosine. Prog Cardiovasc Dis 1989;32:73-97.

48 Smits P, Lenders JWM, Willemsen JJ, Thien T: Adenosine attenuates the response to sympathetic stimuli in man. Hypertension 1991; 18:216-223.

49 Murry CE, Jennings RB, Reimer KA: Preconditioning with ischemia: A delay of lethal cell injury in ischemic myocardium. Circulation 1986;74:1124-1136.

50 Fralix TA, Steenbergen C, London RE, Murphy E: Glibenclamide does not abolish the protective effect of preconditioning on stunning in the isolated perfused rat heart. Cardiovasc Res 1993;27:630-637.

51 Schulz R, Rose J, Heusch G: Involvent of activation of ATP-dependent potassium channels in ischemic preconditioning in swine. Am J Physiol 1994;267:H1341-H1352.
52 Tomai F, Crea F, Gaspardone A, Versaci F, De Paulis R, Penta de Peppo A, Chiariello L, Gioffre PA: Ischemic preconditioning during coronary angioplasty is prevented by glibenclamide, a selective ATP-sensitive $\mathrm{K}^{+}$channel blocker. Circulation 1994;90:700-705.

53 Gross G, Auchampach J: Blockade of ATP-sensitive potassium channels prevents myocardial preconditioning in dogs. Circ Res 1992;70: 223-233.

54 Kubota I, Yamaki M, Shibata T, Ikeno E, Hosoya Y, Tomoike H: Role of ATP-sensitive $\mathrm{K}^{+}$ channels on ECG ST segment elevation during a bout of myocardial ischemia: A study on epicardial mapping in dogs. Circulation 1993;88: 1845-1851.

55 Downey JM, Liu GS, Thornton JD: Adenosine and anti-infarct effects of preconditioning. Cardiovasc Res 1993;27:3-8.
56 Yao Z, Gross GJ: A comparison of adenosineinduced cardioprotection and ischemic preconditioning in dogs: Efficacy, time course, and role of $\mathrm{K}_{\mathrm{ATP}}$ channels. Circulation 1994;89: 1229-1236

57 Taskinen MR, Beltz WF, Harper I, Fields RM, Schonfeld G, Grundy SM, Howard BV: Effects of NIDDM on very low-density lipoprotein triglyceride and apolipoprotein B metabolism: Studies before and after sulfonylurea therapy. Diabetes 1986;35:1268-1277.

58 Calvert GD, Graham JJ, Mannik T, Wise PH, Yeates RA: Effects of therapy on plasma highdensity-lipoprotein-cholesterol concentration in diabetes mellitus. Lancet 1978;ii:66-68.

59 Huupponen RK, Viikari JS, Saarimaa H: Correlation of serum lipids with diabetes control in sulfonylurea-treated diabetic patients. Diabetes Care 1984;7:575-578.

60 Colwell JA: Pathophysiology of vascular disease in diabetes: Effects of gliclazide. Am J Med 1991;90(suppl 6A):505-545.

61 Mühlhauser I, Berger M: Surrogat Marker Trugschlüsse. Dt Ärztebl 1996;93:A3280A3283. 